\title{
Effect of Educational program for nurses on their knowledge regarding obligatory vaccination for
} children

\author{
Heba Boshra Shehata ${ }^{1}$, Gehan Ahmed El-Samman ${ }^{2}$, Sanaa Mahmoud Ahmed ${ }^{3}$
}

1- Assistant Lecturer- Faculty of nursing- Quena - South Valley University

2- Professor of Pediatric Nursing - Faculty of nursing - Cairo University

3- Assistant Professor of Pediatric Nursing - Faculty of Nursing- Minia University

\begin{abstract}
Background: Immunization is one of the most cost-effective interventions for the child health promotion. It is a safe and effective method of preventing many series of major illnesses. Nurses need to be confident, knowledgeable and up to date. A high level of knowledge and practice of immunization in healthcare workers is an important element in achieving and maintaining high vaccine uptake. Aim: Assessing the Effect of Educational program for nurses on their knowledge regarding obligatory vaccination for children. Research design: This study used pre/post Quasiexperimental research design. Sample: All nurses who are working in the (7) health office and centers at Minia city and responsible for vaccination of children the total numbers of nurses were 39 nurses. Setting: The selected vaccination office and centers represented all geographic areas of Minia City as this study was conducted in (7) places. Tools for Data Collection: One of tool was used in this study, structured interview questionnaire in Arabic language. It was composed of the following parts: Part 1: demographic data about nurses including nurses' age, qualification, years of experience and previous training courses about vaccination. Part 2: knowledge assessment questionnaires to assess the nurses' knowledge about vaccination. Results: The finding of the current study revealed that there were statistically significant differences between nurses' knowledge at pre and post- program. Conclusion: The study concluded that the health education program was effective in improving nurses' knowledge in post program than before about general information, infection control, BCG, DPT vaccine and the health education which must be given for parents. Recommendation: The study recommended that the provision of continuing education programs on regular basis is suggested in order to refresh and update nurses' knowledge related to vaccination and infection control measures.
\end{abstract}

Keywords: Educational program, infection control, pediatric immunization, nurses' knowledge.

\begin{abstract}
Introduction
Immunization is one of the most cost-effective interventions for the child health promotion. It is a safe and effective method of preventing many series of major illnesses. Immunization arouses the body's own immune system to defend the individual against different communicable disease such as polio, tuberculosis, diphtheria, pertussis, tetanus, hepatitis B, Hemophilus influenza type B and measles (Swarnkar et al., 2016). Ensuring public and professional confidence is critical to the success of the programs. So, it becomes important to understand the knowledge level and practice of health workers responsible for immunization
\end{abstract} (Asim et al., 2012).

Nurses need to be confident, knowledgeable and up to date. A high level of knowledge and practice of immunization in healthcare workers is an important element in achieving and maintaining high vaccine uptake. Nurses have a major role in advising and promoting immunization, as well as administering vaccinations within the childhood immunization program. All staff involved in vaccine administration should be suitably trained and competent to fulfill the role and be able to provide accurate and up to date information about the diseases and vaccines to their patients, to ensure that their practice is safe and effective and to give a high standard of care (WHO, 2015). All vaccine providers should receive education and competency-based training on vaccine administration before providing vaccines to the public (Guide, Canadian Immunization, 2013).

Nurses responsible for handling vaccines should be familiar with the manufacturer's packaging insert for each vaccine including recommendations for handling, storage, administration site, dosage and route to minimize the risk of vaccine failures (Centers for Disease Control and Prevention (CDC), 2011). Recommendations on P a g e | 175 immunization procedures are based on currently available evidence and experience of best practice. Nurses should follow the professional standards and guidelines (Hockenberry \& Wilson, 2018). There are many barriers against immunization including misinformation about vaccination, adverse event reactions of vaccines and negative attitude toward vaccines. Thus, good knowledge and practice regarding immunization is required. Therefore, it is reasonable for nurses and other health care providers to provide parents with comprehensive information about immunization, which in turn will help to shape positive attitude toward vaccinations and improve their practice (Omotara, et al., 2012).

\section{Significance of the study}

The World Health Organization (WHO) acknowledges that immunization is one of the most effective health investments, estimated at preventing between two and three million deaths each year (The Australian Immunization Handbook, 2018). Egypt vaccinates over 35 million children every year. Estimated national coverage rates of children that are fully immunized (2014) is $91.0 \%$ (UNICEF, 2015) \& (WHO, 2019). Every year in the United States between 3,000 and 4,500 severe vaccine reactions are reported to the Centers for Disease Control. These severe reactions can land somebody in the hospital, the intensive care unit, cause a permanent disability or death. From 1,244 cases of people reported hospitalized 416 cases of people reported a disability, 122 reported deaths, and 388 reported lifethreatening cases (Bob Sears, 2015).

\section{Aim of the Study}

The aim of this study is to assess the effect of educational program for nurses on their knowledge regarding obligatory vaccination for children

Heba B., et al 


\section{Research Hypothesis}

Nurses involved in educational program will have a higher score of knowledge than before the program.

\section{Subjects and Methods \\ Research design:}

This study used pre/post Quasi- experimental research design. A Quasi- experimental research design is one type of experimental design that is very similar to the true experimental design except that its losses one criterion which is control or randomization (Burns \& Grove, 2012)

\section{Setting:}

The selected vaccination office and centers represented all geographic areas of Minia city as this study was conducted in 7 places (all the vaccination centers in Minia City). Four health offices (first health office, Second health office, third health office and fourth health office) in addition to three health centers (Shabab Elmostakbal MCH center \{Minia El-Gedida\}, first health care center and second health care center).

\section{Sample}

The sample involved all nurses who are working in the (7) health office and centers at Minia city and responsible for vaccination of children, the total numbers of nurses were 39 nurses. Numbers of nurses in each heath office and centers as the following:

Four health offices:

- 8 nurses from the first health office

- 9 nurses from the second health office

- 4 nurses from the third health office (western $\mathrm{MCH}$ center)

- 5 nurses from the fourth health office

Three health centers:

- 8 nurses from the Shabab Elmostakbal MCH center ( Minia El-Gedida)

- 3 nurses from the first health care center

- 2 nurses from the second health care center

\section{Inclusion criteria}

All nurses who are responsible for giving vaccination for children and working in the previously mentioned health offices and health centers.

\section{Exclusion criteria}

Nurses who attended training courses about infection control or vaccination less than one year ago weren't included in the sample.

\section{Tool for Data Collection}

Structured Questionnaire in Arabic language and was developed by the researcher after reviewing related literature. It was comprised from two parts:

Part 1: Demographic data about nurses including nurses' age, qualifications, years of experience and previous training courses about vaccination.

Part 2: Knowledge assessment questionnaires: To assess the nurses' knowledge about vaccination. Which involves 66 multiple choice questions and divided into 7 sections: Section 1 contains 11 questions regarding general information about vaccination. Section 2 contains 5 questions about infection control measures. Section 3 contains 11 questions about oral polio vaccine. Section 4 contains 12 questions about BCG vaccine. Section 5 contains 12 questions about pentavalent \{DPT, hepatitis B, Haemophilus influenza type B (Hib) vaccine $\}$. Section 6 contains 12 questions about MMR vaccine. Finally, section 7 which contain 3 questions about vitamin A capsule.

\section{Scoring system:}

- The nurses' knowledge was compared with model key answer and accordingly scored as correct or incorrect answer. A score of one for correct answers and a zero for incorrect answers.

- The total score of knowledge was 66 degrees and the scores were converted into a percentage score. The nurses' knowledge was considered satisfactory if the percentage score is $60 \%$ or more and unsatisfactory if less than $60 \%$.

\section{Validity and Reliability}

- The tool was tested for content validity by a jury of three experts in the pediatric nursing field and necessary modifications were done.

- Reliability of the tool that to be tested by using Cronbach's Alpha, to insure the internal consistency of the tools. Test-retest reliability of a structured interview questionnaire was $(0.75)$.

\section{Pilot study}

A pilot study was conducted on $10 \%$ (4) nurses from the selected centers using the previously mentioned tool, to evaluate their applicability and clarity as well as to determine the time required for filling the data for the tool. Nurses involved in the pilot study excluded from the main study subjects.

\section{The program}

The educational program was designed by the researcher about vaccination and infection control information (vaccine and immunity definitions, types of immunity and vaccines, storage and cold chain system regarding general and specific guidelines for each vaccine, vaccine schedule information about types, child age, sites, route, and dosage for each vaccine, health teaching related to each vaccine and parent education, vaccines waste management and health hazards, precautions and side effects for each type of vaccines, methods of transmission of infection and infection universal precaution hand washing, hand rubbing, wearing gloves and safe disposal $\}$.

\section{1- Preparatory phase Included:}

- An official permission was obtained from the concerned immunization centers authorities to conduct the study. The aim and nature of the study were explained to the administrators and nurses.

- The researcher prepared the following:

- The objective, content of the program, strategies (timetable of sessions, teaching methods, media used, learner's activities and evaluation methods), selected the teaching sitting inside each health office and centers and learning content of the program.

Heba B., et al 
- The program finances (supplied by the researcher) and providing the program resources and facilities such as printed materials, doll, gloves, hand gel, soap, tissue papers, cotton, adhesive tab and syringe.

- The teaching methods and media such as lectures, group discussions, pictures, data show on the researcher's personal laptop, demonstrations and hand out Arabic booklet developed by researcher.

- The data collection tool was constructed (structured questionnaire sheet in Arabic language)

\section{2- Assessment phase included:}

A pre-test was conducted before program implementation by using the knowledge assessment tool. The research investigator attended in each health office or center two days during the rest days (non-vaccination days) according to the availability of nurses' time and according the numbers of nurses inside each center. Through an individual interview with each nurse, the research investigator introduced himself and explained the aim and nature of the study and gave them structured questionnaire to be answered it, in the present of the research investigator for more clarification whenever needed. The duration was $30-45$ mints to fill the tool.

\section{3- Intervention phase included:}

- The program sessions conducted during the rest days (non-vaccination days), it was two days according to the availability of nurses' time and number of nurses in each center. Each group of nurses choose their optimal time for receiving the program whenever they have minimal workload. The centers which contained large number of nurses were scheduled for two smalls groups, the total nurses' groups were 10 groups (each group ranged between 2 to 5 nurses). Two teaching hours for each group at the same day were performed. From nine to eleven O'clock for group one and from eleven to one O'clock for the other group. Each session usually started by a summary of what has been taught during the preceding session.

- The program was conducted over 8 sessions for each group, as the research conducted two sessions per week, the duration for every session was 2 hours to cover all information regarding the vaccination program. the program included definitions of vaccination, immunity, types of vaccines, type of immunity, site and dose, precaution, side effects for each vaccine, storage and cold chain system, vaccine waste management, benefits and risks associated with each vaccine and parent education related each vaccine.

- Method of teaching involved modified lectures, group discussions, pictures, videos shown by using the researcher's personal laptop. Different methods were used to motivate nurses and reinforce correct information such as recognition during the program sessions.

- The researcher developed an Arabic booklet for nurses about immunization. It contained general updated knowledge. Copy of the program booklet was given to each participant nurse before starting the program implementation.

\section{4- Evaluation phase:}

All nurses were reassessed by using the same knowledge assessment tool, immediately after the end of the program and after three months as a follow up phase. The study work was conducted through 4 months starting from July to October 2017.

\section{Ethical consideration}

Approval was obtained from the ethical committee; Faculty of nursing, Minia University. The purpose and nature of the study was explained to the nurses and oral consent was obtained from each of them to participate in this study. They were informed that they can withdraw from the study without giving a reason and they were assured that anonymity and confidentiality of information was protected. Ethics, values, culture, and beliefs were respected.

\section{Statistical analysis}

Data entry was done using compatible personal computer. The statistical analysis was done using SPSS Version 20 statistical software package. Data were presented using descriptive statistics in the form of frequencies and percentages for qualitative variables. Qualitative studied variables were compared using chi-square test. Pearson correlation analysis was used for assessment of the interrelationships between the nurses' knowledge about infection control of procedure, statistical significance difference at $\mathrm{p}$ value $<0.05$.

\section{Results}

Table (1): Demographic Characteristics of the Studied Nurses $(\mathbf{N}=39)$

\begin{tabular}{|c|c|c|c|}
\hline \multirow{2}{*}{\multicolumn{2}{|c|}{ Demographic Data }} & \multicolumn{2}{|c|}{ Total $\mathbf{N}=39$} \\
\hline & & No & $\%$ \\
\hline \multirow[t]{4}{*}{ Age/year } & $20:<30$ & 1 & 2.6 \\
\hline & $30:<40$ & 13 & 33.3 \\
\hline & $40:<50$ & 15 & 38.5 \\
\hline & $>\mathbf{5 0}$ & 10 & 25.6 \\
\hline Mean and SD & \multicolumn{3}{|c|}{$41.5 \pm 9.1$} \\
\hline \multirow[t]{4}{*}{ Years of Experiences } & $5:<10$ & 1 & 2.6 \\
\hline & $10:<15$ & 4 & 10.3 \\
\hline & $15:<20$ & 11 & 28.2 \\
\hline & $>20$ & 23 & 59.0 \\
\hline Mean and SD & \multicolumn{3}{|c|}{$20.02 \pm 4.9$} \\
\hline \multirow[t]{2}{*}{ Qualification: } & Diploma Nurse & 38 & 97.4 \\
\hline & Technical Nurse & 1 & 2.6 \\
\hline \multirow[t]{2}{*}{ Training Courses: } & Nurses didn't attend training & 32 & 82.1 \\
\hline & Nurses attended training & 7 & 17.9 \\
\hline \multirow[t]{2}{*}{ Type of Training Courses $(n=7)$} & Infection control & 5 & 71.4 \\
\hline & Vaccine administration & 2 & 28.6 \\
\hline
\end{tabular}




\begin{tabular}{|l|l|c|c|}
\hline \multicolumn{2}{|c|}{ Demographic Data } & \multicolumn{2}{c|}{ Total N =39 } \\
\cline { 3 - 4 } & No & $\mathbf{\%}$ \\
\hline Date of Training Courses (n=7) & Less than one year & 0 & 0 \\
\cline { 2 - 4 } & More than one year & 7 & 100 \\
\hline
\end{tabular}

Table (1) illustrated that more than one third of the studied nurses $(38.5 \%)$ their age was ranged between $40:<50$ years old with a mean and SD of age $41.5 \pm 9.1$. More than one quadrant of them (28.2\%) had years of experience ranged from 15 to $<20$ years with a mean and SD of years of experience 20.02 \pm 4.9 . Majority of the nurses $(97.4 \%)$ had diploma degree in nursing. More than four fifth (82.1\%) of the studied nurses didn't attend any training courses. On the other hand, less than three fourth of nurses $(71.4 \%)$ who exposed to training courses, attended training courses related to infection control. All nurses $(100 \%)$ attended the training courses for during a period of one and more than one year before this study.

Table (2): Nurses' knowledge about General Information of Vaccination Pre, Immediate and Follow up of the Educational $\operatorname{Program}(\mathbf{N}=39)$

\begin{tabular}{|c|c|c|c|c|c|c|c|c|c|}
\hline \multirow{2}{*}{\multicolumn{2}{|c|}{ Items }} & \multicolumn{2}{|c|}{ Pre } & \multicolumn{2}{|c|}{ Immediate } & \multicolumn{2}{|c|}{ Follow up } & \multirow{2}{*}{$\chi^{2}$} & \multirow{2}{*}{$\mathbf{P}$} \\
\hline & & NO & $\%$ & NO & $\%$ & NO & $\%$ & & \\
\hline \multirow{2}{*}{$\begin{array}{l}\text { The benefit of routine vaccinations for } \\
\text { children }\end{array}$} & Incorrect & 3 & 7.7 & 0 & 0.0 & 0 & 0.0 & \multirow{2}{*}{6.1} & \multirow{2}{*}{0.046} \\
\hline & Correct & 36 & 92.3 & 39 & 100 & 39 & 100 & & \\
\hline \multirow{2}{*}{$\begin{array}{l}\text { Role of vaccination in protecting the child } \\
\text { from the disease }\end{array}$} & Incorrect & 11 & 28.2 & 3 & 7.7 & 10 & 25.6 & \multirow{2}{*}{25.9} & \multirow{2}{*}{$0.001 * * *$} \\
\hline & Correct & 28 & 71.8 & 36 & 92.3 & 29 & 74.4 & & \\
\hline \multirow{2}{*}{$\begin{array}{l}\text { Reasons of giving vaccines doses at a } \\
\text { specific age }\end{array}$} & Incorrect & 24 & 61.5 & 0 & 0.0 & 4 & 10.3 & \multirow{2}{*}{8.4} & \multirow{2}{*}{$0.014 *$} \\
\hline & Correct & 15 & 38.5 & 39 & 100 & 35 & 89.7 & & \\
\hline \multirow{2}{*}{$\begin{array}{l}\text { Reasons of giving vaccines at specific } \\
\text { intervals }\end{array}$} & Incorrect & 8 & 20.5 & 0 & 0.0 & 5 & 12.8 & \multirow{2}{*}{36.2} & \multirow{2}{*}{$0.001 * * *$} \\
\hline & Correct & 31 & 79.5 & 39 & 100 & 34 & 87.2 & & \\
\hline \multirow{2}{*}{$\begin{array}{l}\text { Reasons of given more than one dose of } \\
\text { the same vaccine }\end{array}$} & Incorrect & 11 & 28.2 & 3 & 7.7 & 4 & 10.3 & \multirow{2}{*}{27.4} & \multirow{2}{*}{$0.001 * * *$} \\
\hline & Correct & 28 & 71.8 & 36 & 92.3 & 35 & 89.7 & & \\
\hline \multirow{2}{*}{$\begin{array}{l}\text { Purpose of using the combined vaccines } \\
\text { (one dose containing several different } \\
\text { vaccines) }\end{array}$} & Incorrect & 29 & 74.4 & 0 & 0.0 & 2 & 5.1 & \multirow[b]{2}{*}{25.1} & \multirow[b]{2}{*}{$0.001 * * *$} \\
\hline & Correct & 10 & 25.6 & 39 & 100 & 37 & 94.9 & & \\
\hline \multirow{2}{*}{$\begin{array}{l}\begin{array}{l}\text { Vaccines not given permanently to } \\
\text { children }\end{array} \\
\end{array}$} & Incorrect & 28 & 71.8 & 5 & 12.8 & 4 & 10.3 & \multirow{2}{*}{20.1} & \multirow{2}{*}{$0.001 * * *$} \\
\hline & Correct & 11 & 28.2 & 34 & 87.2 & 35 & 89.7 & & \\
\hline \multirow{2}{*}{$\begin{array}{l}\text { Vaccines that contraindicated to children } \\
\text { with HIV }\end{array}$} & Incorrect & 15 & 38.5 & 0 & 0.0 & 4 & 10.3 & \multirow{2}{*}{18.4} & \multirow{2}{*}{$0.001 * * *$} \\
\hline & Correct & 24 & 61.5 & 39 & 100 & 35 & 89.7 & & \\
\hline \multirow{2}{*}{ 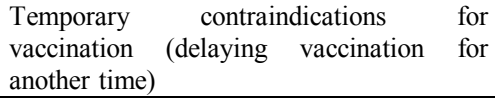 } & Incorrect & 2 & 5.1 & 0 & 0.0 & 4 & 10.3 & \multirow[b]{2}{*}{4.6} & \\
\hline & Correct & 37 & 94.9 & 39 & 100 & 35 & 89.7 & & 0,10 \\
\hline $\begin{array}{lll}\text { Conditions } & \text { which } & \text { considers }\end{array}$ & Incorrect & 16 & 41 & 3 & 7.7 & 3 & 7.7 & 20.5 & $0001 * * *$ \\
\hline contraindication for vaccination & Correct & 23 & 59 & 36 & 92.3 & 36 & 92.3 & 20.5 & $0.001 \times 5$ \\
\hline Necessary to vaccinate the child & Incorrect & 1 & 5.1 & 0 & 0.0 & 1 & 2.6 & 10 & 0.601 \\
\hline & Correct & 38 & 97.4 & 39 & 100 & 38 & 97.4 & 1.0 & \\
\hline
\end{tabular}

$\chi^{2}:$ chi-square test $* \mathrm{P} \leq 0.05$

$* * \mathrm{P} \leq 0.01$

$* * * \mathrm{p} \leq 0.001$

Regarding nurses' knowledge about general information of vaccination table (2) proved that, there were highly statistical significant differences between pretest, immediate and follow-up posttest in most of items regarding general information about vaccination (role of vaccination in protecting child from diseases, reason of giving vaccines at specific intervals, reason of giving more than one dose of the same vaccine, purpose of using the combined vaccines, the permanent contraindication of vaccination for children with HIV, and the conditions which consider not contraindicated for children vaccination) $(\mathrm{P}=0.001)$.

Table (3): Nurses' knowledge about General Information Regarding Infection Control Pre, Immediate and Follow up of Educational Program (N=39)

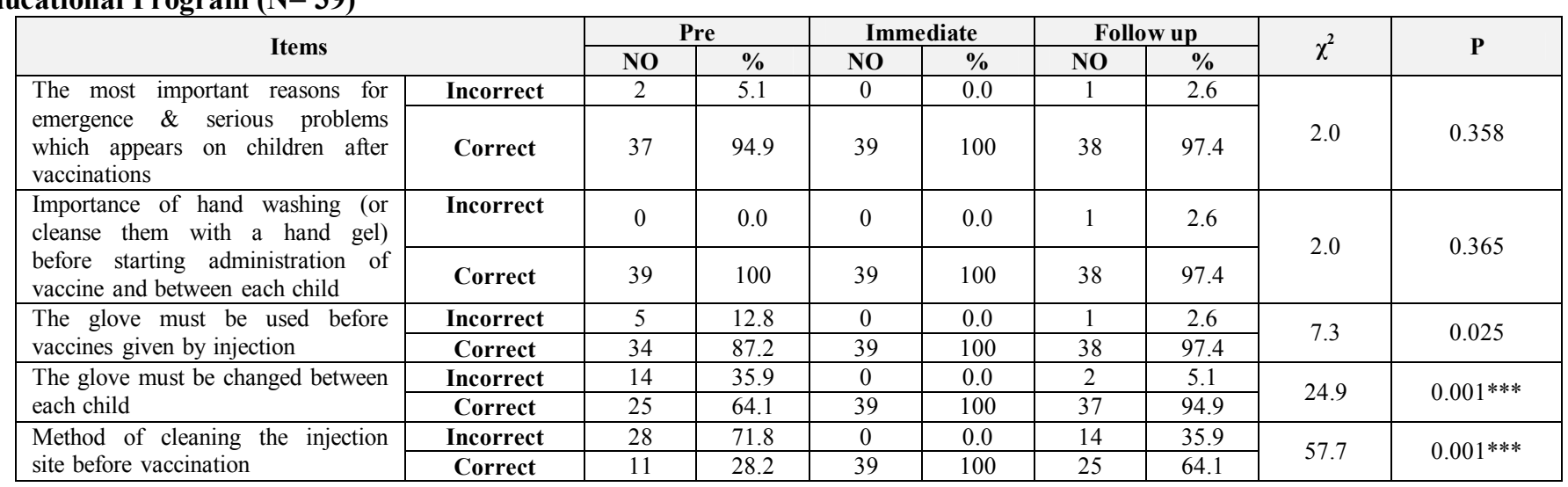

$\chi^{2}:$ chi-square test $* \mathrm{P} \leq 0.05$

$* * \mathrm{P} \leq 0.01$

$* * * \mathrm{p} \leq 0.001$

Concerning nurses' knowledge about infection control table (3) clarified that there were highly statistical significance differences were observed between pretest, immediate and follow up posttests in two items only which are, gloves must be changed between each child and the methods of cleaning the injection site before vaccination at $p$-value $=0.001$. On the other hand, no statistical significance differences were detected between pretest, immediate and follow up posttests about causes of serious vaccine 
Minia Scientific Nursing Journal (Print) (ISSN 2537-012X) Vol. (6) No. (1) December 2019

problems, hand washing and wearing gloves. As the majority of nurses had correct information about most important reason for emergency and serious problem, important of hand washing and gloves must be used during vaccination in pretest $(94.9 \%, 100 \%$ \& $87.2 \%$ respectively), while all of them $(100 \%)$ had correct information in immediate posttest with no statistical significance differences between pre, immediate and follow up posttests.

Table (4): Nurses' Total Score of Knowledge about Vaccination and Infection Control Pre, Immediate, and Follow up of Educational Program N=39

\begin{tabular}{|c|c|c|c|c|c|c|c|c|}
\hline \multirow{2}{*}{ Items } & \multicolumn{2}{|c|}{ Pre } & \multicolumn{2}{|c|}{ Immediate } & \multicolumn{2}{|c|}{ Follow up } & \multirow{2}{*}{$\chi^{2}$} & \multirow{2}{*}{$\mathbf{P}$} \\
\hline & $\mathbf{N}$ & $\%$ & $\mathbf{N}$ & $\%$ & $\mathbf{N}$ & $\%$ & & \\
\hline \multicolumn{9}{|c|}{ General Information about vaccination } \\
\hline Satisfactory & 33 & 84.6 & 37 & 94.9 & 22 & 56.4 & \multirow{2}{*}{18.4} & \multirow{2}{*}{$0.001 * * *$} \\
\hline Un satisfactory & 6 & 15.4 & 2 & 5.1 & 17 & 43.6 & & \\
\hline \multicolumn{9}{|l|}{ Infection Control Information } \\
\hline Satisfactory & 28 & 71.8 & 39 & 100 & 36 & 92.3 & \multirow{2}{*}{15.7} & \multirow{2}{*}{$0.003 * * *$} \\
\hline Un satisfactory & 11 & 28.2 & 0 & 0 & 3 & 7.7 & & \\
\hline \multicolumn{9}{|l|}{ Oral Polio Vaccine } \\
\hline Satisfactory & 33 & 84.6 & 36 & 92.3 & 34 & 87.2 & \multirow{2}{*}{1.1} & \multirow{2}{*}{0.5} \\
\hline Un satisfactory & 6 & 15.4 & 3 & 7.7 & 5 & 12.8 & & \\
\hline \multicolumn{9}{|l|}{ BCG Vaccine } \\
\hline Satisfactory & 35 & 89.7 & 39 & 100 & 28 & 71.8 & \multirow{2}{*}{14.2} & \multirow{2}{*}{$0.001 * * *$} \\
\hline Un satisfactory & 4 & 10.3 & 0 & 0.0 & 11 & 28.2 & & \\
\hline \multicolumn{9}{|l|}{ Pentavalent/DPT Vaccine } \\
\hline Satisfactory & 35 & 89.7 & 39 & 100 & 23 & 59 & \multirow{2}{*}{25.1} & \multirow{2}{*}{$0.001 * * *$} \\
\hline Un satisfactory & 4 & 10.3 & 0 & 0.0 & 16 & 41 & & \\
\hline \multicolumn{9}{|l|}{ MMR Vaccine } \\
\hline Satisfactory & 34 & 87.2 & 37 & 94.9 & 38 & 97.4 & \multirow{2}{*}{3.4} & \multirow{2}{*}{0.1} \\
\hline Un satisfactory & 5 & 12.8 & 2 & 5.1 & 1 & 2.6 & & \\
\hline \multicolumn{9}{|l|}{ Vitamin A capsule } \\
\hline Satisfactory & 38 & 97.4 & 37 & 94.9 & 39 & 100 & \multirow{2}{*}{2.05} & \multirow{2}{*}{0.3} \\
\hline Un satisfactory & 1 & 2.6 & 2 & 5.1 & 0 & 0 & & \\
\hline \multicolumn{9}{|l|}{ Total Score } \\
\hline Satisfactory & 31 & 79.5 & 37 & 94.9 & 33 & 84.6 & \multirow{2}{*}{4.1} & \multirow{2}{*}{0.1} \\
\hline Un satisfactory & 8 & 20.5 & 2 & 5.1 & 6 & 15.4 & & \\
\hline
\end{tabular}

Table (4) showed that nurses' knowledge was significantly improved immediately and during follow up posttests after the educational program than preprogram test, regarding their general information about vaccination $\left(\chi^{2}=18.4, \mathrm{P}=0.001\right)$, infection control $\left(\chi^{2}=15.7, \mathrm{P}=0.003\right), \mathrm{BCG}$ vaccine $\left(\chi^{2}=14.2, \mathrm{P}=0.001\right)$ and pentavalent vaccine $\left(\chi^{2}=25.1, \mathrm{P}=0.001\right)$. While no statistical significance differences were detected between nurse's knowledge in the pre and posttests concerning oral polio, MMR vaccine and vitamin A capsule as well as in the total information.

Table (5): Relation between Nurses' Demographic Data and Their Total Score of Knowledge $(\mathrm{N}=39)$

\begin{tabular}{|c|c|c|c|}
\hline Items & \multicolumn{3}{|c|}{ Knowledge } \\
\hline Age & Pre & Immediate & Follow up \\
\hline $\mathbf{R}$ & -0.49 & -0.23 & -0.45 \\
\hline $\mathbf{P}$ & $0.001 * * *$ & 0.08 & $0.001 * * *$ \\
\hline \multicolumn{4}{|l|}{ Qualification } \\
\hline $\mathbf{R}$ & 0.27 & 0.12 & 0.22 \\
\hline $\mathbf{P}$ & 0.09 & 0.3 & 0.1 \\
\hline \multicolumn{4}{|l|}{ Years of experience } \\
\hline $\mathbf{R}$ & -0.51 & -0.19 & -0.37 \\
\hline $\mathbf{P}$ & $0.001 * * *$ & 0.2 & $0.01 * *$ \\
\hline \multicolumn{4}{|l|}{ Training courses } \\
\hline $\mathbf{R}$ & -0.10 & 0.33 & 0.07 \\
\hline $\mathbf{P}$ & 0.4 & $0.01 * *$ & 0.6 \\
\hline
\end{tabular}

$\mathrm{R}$ : correlation $\quad * \mathrm{P} \leq 0.05 \quad * * \mathrm{P} \leq 0.01 \quad * * * \mathrm{p} \leq 0.001$

Regarding correlation between nurses' demographic data and their knowledge table (5) clarified that, nurses' age had negative correlation with their knowledge in the pre-program test $(\mathrm{R}=-0.49, \mathrm{P}=0.001)$, and follow up posttest $(\mathrm{R}=-0.45, \mathrm{P}=0.001)$. Another negative correlation was found between years of experiences and their knowledge in the pretest $(\mathrm{R}=-0.51, \mathrm{P}=0.001)$ and follow up posttest $(\mathrm{R}=-0.37 \mathrm{P}=0.01)$. While a positive correlation was detected between nurses' knowledge and their training courses in the immediate posttest of the educational program $(\mathrm{R}=0.33, \mathrm{P}=0.01)$.

\section{Discussion}

Life of many children can be saved by successful immunization, but its success depend on knowledge and practice of health workers how are vaccinating. Vaccine safety issues and the need for multiple injections have increased the concerns and anxiety associated with immunizations. Healthcare providers need to display confidence and establish an environment that promotes a sense of security and trust for the patient and family, utilizing a variety of techniques to minimize the stress and discomfort associated with receiving injections. This is particularly important when administering vaccines to children (The California Department of Health Services, 2016). 
The results of the current study revealed that all nurses in the study sample were females, and this finding is consistent with Plumridge, Goodyear-Smith \& Ross (2008) who assessed parents and nurses during the immunization of children in New Zealand vaccination centers and reported that all the immunization providers were female practicing nurses. This may be because the registration in nursing school started at the 21th country for females only, but recently the male nurses preferred to work in hospitals rather than the vaccination centers.

Regarding nursing qualification, the present study's results showed that the most of nurses had diploma degree in nursing and this result matches with Fahim et al., (2011) who assessed nurses' practice regarding to infection control during vaccination in children at El-Minia and reported that all nurses' qualification was diploma nurse. This might be because in Egypt the majority of nurses with diploma degree in nursing especially those who are working in the immunization centers because the work is easy and have one shift only so, it is matching with the diploma nurse capabilities.

Concerning nurses' socio-demographic data, the current study illustrated that more than one third of the study sample their age was ranged from 40-50 years with Mean \pm SD (41.5 \pm 9.1$)$. And slightly more than one quadrant of nurses had years of experience ranged from 15-20 years with Mean $\pm \mathrm{SD}(20.02 \pm 4.9)$. This result is nearest to the result obtained by Masika, Atieli \& Were, (2016) who assessed knowledge, perceptions, and practice of nurses on surveillance of adverse events following childhood immunization in Nairobi, Kenya and reported that the mean age of nurses was (39.5 years) and the average years of experience of nurses was (16.4) years. On the other hand, the current result contradicted with Fashafsheh, et al., (2015) who studied knowledge and practice of nursing staff towards infection control measures in the Palestinian hospitals and found that $(64.2 \%)$ of the studied nurses' aged between 20-30 years and the years of experience were less than 5 years was constituted in $(43.9 \%)$ of the total sample.

Regarding training courses about infection control and vaccination, it was noticed that $(82.1 \%)$ of the studied nurses did not attend any training courses, this may be attributed to the shortage in the nursing staff, so the health centers could not let them to attend any training courses to prevent interruption of the work due to their attendance. Our results agreed with findings of Eskander, Morsy \& Elfaky, (2013) who studied the intensive care nurses' knowledge \& practices regarding infection control standard precautions at a selected Egyptian cancer hospital, and reported that $(63.6 \%)$ of nurses had not attended any training courses related to universal precautions, and standard precautions such as (hand washing, wearing gloves, correct sharps handling and aseptic technique) which are to be followed at all times by nurses.

There were highly statistically significant differences between pretest, immediate and follow-up posttests in most of items regarding general information about vaccination as the results showed that the lowest percentage of nurses answered the permanent contraindication of vaccination correctly. This result matches with those observed by Al-Ayed \& Sheik, (2006) who mentioned that it is necessary to educate and provide the vaccine providers with updates and reviews of true and false contraindications for immunization, and the development of clinic guidelines on appropriate reasons to withhold immunization, to avoid missed opportunities that may be attributable to deficiencies in the provider's knowledge of the immunization schedule and true vaccine contraindications as the study surveyed 313 health professional, about (69.5\%) of the nurses' sample didn't answer the questions regarding possible precautions or contraindications of vaccination correctly. The finding of the present study may be due to lack of nurses' knowledge regarding different precautions and contraindication for each vaccine related to lack of training programs about vaccination.

The current study showed that nurses' knowledge regarding infection control information considered satisfactory as the majority of nurses had correct information about the most of infection control questions during the pretest and this result disagreed with Eskander, Morsy \& Elfaky, (2013) who reported that $(63.6 \%)$ of the studied sample had unsatisfactory knowledge level regarding infection control measures.

It was found that the highest percentage of nurses had satisfactory knowledge about general information of vaccination and infection control $(84.6 \%$, $71.8 \%$ respectively) in the preprogram test. Their knowledge improved significantly immediately and during the follow up posttests after the educational program than the preprogram test. Our results were better than that reported by Al-Ayed (2005) who studied 479 respondents, $(60.5 \%)$ of them were nurses to assess knowledge and practices of childhood immunization among primary health care providers in Riyadh City, and he documented that $(66 \% \& 86.1 \%)$ have satisfactory knowledge regarding general information of vaccination and infection control information respectively.

The current study detected that the majority of nurses had satisfactory knowledge in the preprogram test about oral polio, BCG, pentavalent and MMR vaccines. Those findings were congruent with results of El Shazly et al., (2016) study about knowledge of healthcare providers regarding each vaccine, found that majority of nurses had a satisfactory level of knowledge for all typed of vaccines except for Haemophilus influenza type B (Hib) vaccine.

Regarding correlation between nurses' demographic data and their knowledge, the present study clarified that, nurses age had negative correlation with their knowledge in pre-program and post program follow up posttest. This finding is in the same line with the results of a study conducted by Tomboloni et al., (2019) who assessed the knowledge, attitude and disinformation regarding vaccination and immunization practices among healthcare workers of a third-level pediatric hospital and found that the younger nurses had higher statistically significant of adequate knowledge and practice, compared to the older ones. From the researcher's point of view this may be because they have updated knowledge and good practice as they were newly graduated and have updated knowledge and have greater desire to learn than the older nurses.

A negative correlation was found between nurses' years of experiences and their knowledge in the preprogram and follow up posttest. This result matches with findings of Swarnkar et al., (2016) who assessed knowledge and practice 
about immunization among health care providers and mentioned that, there was negative correlation between knowledge and practice of health workers with increase in duration of years of experience. Also, these findings were congruent with those obtained by Metwally, Donia \& Abdel Aziz (2016) who indicated that nurses with 5 to less than 10 years of experience had higher mean percent knowledge score than those with more than 10 years of experience. From the researcher point of view this finding may be because younger nurses have updated knowledge as they were newly graduate. The result of the present study contrary the finding of study which conducted in Thailand by Widsanugorn et al., (2011) who assessed the health care worker's knowledge and practice regarding expanded program about immunization and found that significant improvement occurs in knowledge and practice with increase in duration of occupation.

A positive correlation was detected in the present study between nurse's knowledge and their training courses immediate educational program posttest. This finding supported by El Shazly et al., (2016) who revealed that receiving training courses has a significance effect on total knowledge of health care providers about vaccination. On the other hand, the result of Brown, Oluwatosin \& Ogundeji (2017) contradicted with the current study as they mentioned "immunization providers' age, years of experience of immunization practice and previous attendance of immunization training did not have any significant association with their performance in all the assessments conducted". From the researcher's point of view, it is very important to planed regular workshops about infection control during vaccination, masy be due to attending of training courses increase their knowledge and practice.

A highly statistical significance differences were detected between knowledge of nurses in the pre, immediate and follow up posttest. This result is supported the hypothesis of this study as observed that the nurses' knowledge improved immediately after educational program and during the follow up phase. The finding of the present study were consistent with Brown, Oluwatosin \& Ogundeji (2017) who revealed that a statistically significant improvement in the participant's knowledge and practice in all the three parameters of the study evaluation (immediate, after 3 months \& after 6 months) from the training program than the pre intervention phase assessment.

\section{Conclusion}

The study concluded that the health education program was effective in improving nurse's knowledge in post program than before regarding general information of vaccination, infection control, BCG, DPT vaccine and component of health education given for parents.

\section{Recommendations}

- Provision of continuing education programs on regular basis is suggested in order to refresh and update nurses' knowledge, as well as reinforce proper practice related to infection control.

- There should be a continuous supervision and periodic evaluation of nurses that is needed to determine any deficiency in their knowledge or performance. Provision of adequate resources and facilities, (such as protective barriers, sinks, soap, towels, etc.) and equipment related to procedures in health care settings.
- Every vaccination center of infection control should be follow-up the application of standard guidelines related to infection control measures, vaccination safety measures and evaluation of the policies and procedures.

\section{References}

1) Al-Ayed, I. H. (2005). Knowledge and practices of childhood immunization among primary health care providers in Riyadh City: Part I: Handling and administration of vaccines. Curr Pediatr Res, 9(1\&2), 15-21.

2) Al-Ayed, I. H., \& Sheik, S. (2006). Knowledge \& practices of childhood immunization among primary health care providers in Riyadh city: Part iiprecautions and contraindications to vaccination. Journal of family \& community medicine, 13(1), 19.

3) Asim, M., Malik, N., Yousaf, H., Gillani, I., \& Habib, N. (2012). An assessment of parental knowledge, belief and attitude toward childhood immunization among minorities in rural areas of district Faisalabad, Pakistan. Mediterranean Journal of Social Sciences, 3(11), 153-159.

4) Bob Sears. (2015). What CDC statistics say about vaccine-related illnesses, injuries and death, CDC, Vaccine Adverse Event Reporting System. Retrieved from: http://www.politifact/personalities/bob.sears.

5) Brown, V. B., Oluwatosin, O. A., \& Ogundeji, M. O. (2017). Impact of training intervention on immunization providers' knowledge and practice of routine immunization in Ibadan, south-western Nigeria: a primary health care experience. Pan African Medical Journal, 26(216).

6) Burns, N \& Grove, S. (2012). Understanding nursing research building an Evidence-based practice. 5th ed. USA: Elsevier, Pp. 35-61.

7) Centers for Disease Control and Prevention (CDC). (2011). General Recommendations on Immunization Recommendations of the Advisory Committee on Immunization Practices (ACIP). MMWR Morb Mortal Wkly Rep 60 (RR-2):1-61.

8) El Shazly, H. M., Khalil, N. A., Ibrahem, R. A., \& Wahed, S. A. A. (2016). Knowledge and practice of healthcare providers as regards routine children vaccination in primary healthcare facilities of Quewisna District, Menoufia Governorate. Menoufia Medical Journal, 29(4), 1018.

9) Eskander, H. G., Morsy, W. Y., \& Elfeky, H. A. (2013). Intensive care nurses' knowledge $\&$ practices regarding infection control standard precautions at a selected Egyptian Cancer Hospital. Prevention, 4(19), 160-174.

10) Fahim, F. M., El-kreem, H. I. A., Marzouk, S. A., \& Shehata, H. B. (2011). Nurses practices regarding to infection control during vaccination in children at ElMinia. AAMJ, 9(3).

11) Fashafsheh, I., Ayed, A., Eqtait, F., \& Harazneh, L. (2015). Knowledge and Practice of Nursing Staff towards Infection Control Measures in the Palestinian Hospitals. Journal of Education and Practice, 6(4), 79-90. 
12) Guide, Canadian immunization. (2013). Part 1-Key Immunization Information; Blood products, human immune globulin and timing of immunization.

13) Hockenberry, M. J., \& Wilson, D. (2018). Wong's nursing care of infants and children-E-book. Elsevier Health Sciences.Retrieved from:

14) https://books.google.com.eg/books?hl=en\&lr=\&id=w 7RqDwAAQBAJ\&oi $=$ fnd\&pg $=$ PP1\&dq $=$ Marilyn $+\mathrm{J}$. $\mathrm{H}+$ and + David+Wilson, $+(2017 .+$ Wong $\% 27 \mathrm{~s}+$ Nursin $\mathrm{g}+\mathrm{Care}+\mathrm{of}+$ Infants + and + Children\&ots $=$ uIdQbznDJ $\mathrm{X} \& \operatorname{sig}=\mathrm{KxIYj}-$ 0j4YS6aQdBMPBvJPVKLPk\&redir_esc=y\#v=onepa ge\&q=Marilyn $\% 20 \mathrm{~J} . \mathrm{H} \% 20$ and $\% 20$ David $\% 20$ Wilson $\% 2 \mathrm{C} \% 20$ (2017.\%20Wong's $\% 20$ Nursing $\% 20$ Care $\% 2$ 0of $\% 20$ Infants $\% 20$ and $\% 20$ Children $\& \mathrm{f}=$ false.

15) Masika, C. W., Atieli, H., \& Were, T. (2016). Knowledge, Perceptions, and Practice of Nurses on Surveillance of Adverse Events following Childhood Immunization in Nairobi, Kenya. BioMed research international, 2016, 3745298. doi: $10.1155 / 2016 / 3745298$.

16) Metwally, H., Donia, S. A., \& Aziz, T. A. (2016). Safety Measures for Patients Undergoing Upper GIT Endoscopy. Alexandria Scientific Nursing Journal, 18(1), 17-42.

17) Omotara, B. A., Okujagu, T. F., Etatuvie, S. O., Beida, O., \& Gbodossou, E. (2012). Assessment of knowledge, attitude and practice of stakeholders towards immunization in Borno State, Nigeria: A qualitative approach. J Community Med Health Educ, 2(9), 1000181.

18) Plumridge, E., Goodyear-Smith, F. A., \& Ross, J. (2008). Parents and nurses during the immunization of children-where is the power? A conversation analysis. Family practice, 25(1), 14-19.

19) Swarnkar, M., Baig, V. N., Soni, S. C., Shukla, U. S., \& Ali, J. (2016). Assessment of knowledge and practice about immunization among health care providers. Community Med, 7(4), 281285.

20) The Australian Immunization Handbook. (2018). 10th edition. Retrieved from: http://www.practiceassist.com.au/PracticeAssist/medi a/ResourceLibrary/Programs $\% 20$ and $\% 20$ National $\% 2$ 0Schemes/Immunise-The-Australian-ImmunisationHandbook-10th-Edition.pdf.

21) The California Department of Health Services. (2016). Immunization Branch has Developed a Complete Package of Resources on Vaccine Administration. pink book. PP.D-1, D-13.Retrieved from: http://www.immunize.org/iztech/index.htm.

22) Tomboloni, C., Tersigni, C., de Martino, M., Dini, D., González-López, J. R., Festini, F. \& Ciofi, D. (2019). Knowledge, attitude and disinformation regarding vaccination and immunization practices among healthcare workers of a third level paediatric hospital. Italian journal of pediatrics, 45(1), 104.

23) UNICEF. (2015). Children in Egypt: a statistical digest, UNICEF Egypt, Cairo, Retrieved from: Egypt. www.unicef.org/egypt.

24) Widsanugorn, O., Suwattana, O., Harun-Or-Rashid, M., \& Sakamoto, J. (2011). Healthcare workers' knowledge and practices regarding expanded program on immunization in Kalasin, Thailand. Nagoya journal of medical science, 73(3-4), 177.

25) World Health Organization (WHO). (2015). Department of Immunization \& Biologicals. Immunization in practice: A practical guide for health staff.Retrieved from: www.immunise.health.gov.au/internet/immunise/pub lishing.nsf/Content/Handbook10-home.

26) World Health Organization (WHO). (2019). Data statistics and graphics. Country selection form (Immunization profile-Egypt). Retrieved from: https://www.who.int/immunization/monitoring_surve illance/data/en/ 